TITLE:

\title{
Kinetic behavior of liquefaction of Japanese beech in subcritical phenol.
}

$\operatorname{AUTHOR}(S)$ :

Mishra, Gaurav; Saka, Shiro

\section{CITATION:}

Mishra, Gaurav ... [et al]. Kinetic behavior of liquefaction of Japanese beech in subcritical phenol.. Bioresource technology 2011, 102(23): 10946-10950

ISSUE DATE:

2011-12

URL:

http://hdl.handle.net/2433/151880

\section{RIGHT:}

(C) 2011 Elsevier Ltd.; This is not the published version. Please cite only the published version.; この論文は出版社版でありません。引用の際に は出版社版をご確認ご利用ください。 


\title{
Kinetic Behavior of Liquefaction of Japanese Beech in Subcritical Phenol
}

\author{
Gaurav Mishra $^{\mathrm{a}}$ and Shiro Saka ${ }^{\mathrm{a}, *}$ \\ ${ }^{a}$ Department of Socio-Environmental Energy Science, Graduate School of Energy \\ Science, Kyoto University, Yoshida-honmachi, Sakyo-ku, Kyoto 606-8501, Japan
}
"Corresponding Author: Shiro Saka, Tel/Fax: +81-75-753-4738, Email: saka@energy.kyoto-u.ac.jp

\begin{abstract}
Non-catalytic liquefaction of Japanese beech (Fagus crenata) wood in subcritical phenol was investigated using a batch-type reaction vessel. After samples were treated at $160^{\circ} \mathrm{C} / 0.9 \mathrm{MPa}-350^{\circ} \mathrm{C} / 4.2 \mathrm{MPa}$ for $3-30 \mathrm{~min}$, they were fractionated into a phenolsoluble portion and phenol-insoluble residues. These residues were then analyzed for their chemical composition. Based on the obtained data, the kinetics for liquefaction was modeled using first-order reaction rate law. Subsequently, the liquefaction rate constants of the major cell wall components including cellulose, hemicellulose and lignin were determined. The different kinetic mechanisms were found to exist for lignin and cellulose at two different temperature ranges, lower $160-290^{\circ} \mathrm{C}$ and higher $310-350^{\circ} \mathrm{C}$, whereas for hemicellulose, it was only liquefied in the lower temperature range. Thus, the liquefaction behaviors of these major cell wall components highlighted hemicellulose to be the most susceptible to liquefaction, followed by lignin and cellulose.
\end{abstract}

Keywords: Japanese Beech; Subcritical Phenol; Cell Wall Components; Non-catalytic Liquefaction of Wood 


\section{Introduction}

The recent changes in oil prices and the increasing concerns of a petroleum-deprived future are driving the fuel market towards innovative and sustainable solutions (Damartzis and Zabaniotou, 2011). In such a situation, woody biomass known as renewable resources can be used as an alternative to the continuously-depleting fossil fuels (Yamazaki et al., 2006) as well as petroleum-derived chemicals (Lee and Ohkita, 2003). Thus, for such alternatives, the liquefaction of lignocellulosic biomass has been tried and investigated with various polyhydric alcohols (Hassan and Shukry, 2008; Yan et al., 2010), and phenol using acidic or alkaline catalyst at various treatment conditions (Maldas and Shiraishi, 1997, Alma et al., 1998). Liquefaction of lignocellulosic biomass with various organic solvents such as polyols (ethylene glycol, polyethylene glycol, etc.) with addition of catalysts was also investigated (Yao et al., 1994).

However, these works have been carried out with catalysts. Thus, post-treatment becomes complicated and environmental burden would be increased. Therefore, with keeping focus on biomass utilization, a new approach of liquefying the whole biomass was developed by supercritical fluid technologies (Minami and Saka, 2003, Wen et al., 2009). One representative example is non-catalytic liquefaction of wood with supercritical alcohols for its effective and efficient utilization (Saka, 2006, Minami et al., 2003, Minami and Saka, 2005, Yamazaki et al., 2006). It was reported in the literature (Minami and Saka, 2005) that more than $90 \%$ of wood could be decomposed and liquefied when treated with methanol at $350^{\circ} \mathrm{C} / 43 \mathrm{MPa}$ for $30 \mathrm{~min}$. 
This supercritical fluid technology is one of the potential technologies to convert biomass to liquefied substances as valuable fuels and chemicals (McKendry, 2002). Through this liquefaction, all major cell wall components of biomass such as cellulose, hemicellulose and lignin are converted to low-molecular weight compounds. Cellulose and hemicelluloses are converted to various monosaccharides apart from decomposed products like 5-HMF and furfural. Whereas, lignin is converted to many phenolic compounds such as coniferyl alcohol, sinapyl alcohol etc, and can be expected to be used in many useful potential lignin-based applications such as preparation of resins, adhesives etc as done by catalytic systems (Alma et al., 1998).

The non-catalytic treatment of biomass with various kinds of alcohols is reported to need a prolonged treatment time of about 30min for its liquefaction (Minami et al., 2003). Hence, phenol as a solvent was primarily selected so as to evaluate the potential to shorten the treatment time. In addition to this, the usage of phenol as a solvent has gotten different benefits. At subcritical conditions, phenol is expected to have low dielectric constant and to behave as non-polar organic solvent. Therefore, the use of phenol at subcritical conditions is expected to readily dissolve relatively high molecular weight products from cellulose, hemicellulose and lignin without using any catalysts. On the other hand, phenol is also used as a solvent to convert biomass to various biomass-based wood chemicals and to plasticize it for the synthesis of various biomaterials like polyurethane foams, novolok-type phenolic resins, adhesives etc. Therefore, the use of phenol as a solvent to achieve complete utilization of wood was hereby suggested under catalytic liquefaction. 
In this study, therefore, as a further approach, phenol was selected for noncatalytic liquefaction in its subcritical state and its kinetic behaviors of these three cell wall components were investigated so as to know the liquefaction mechanism of these components.

\section{Materials and methods}

\subsection{Subcritical phenol treatment}

The air-dried wood flours ( 80 mesh pass) of matured Japanese beech (Fagus crenata) was prepared from sapwood portion using Wiley mill. The flour samples were then extracted with reagent grade acetone purchased from Nacalai Tesque Inc., Japan. Such extracted samples were oven-dried for 12 hours at $105^{\circ} \mathrm{C}$ and then kept in desiccator to cool down. Approximately 150mg of such oven-dried sample and $4.9 \mathrm{ml}$ of reagent grade phenol from Nacalai Tesque Inc., Japan, were fed into a 5-ml batch-type cylindrical shaped reaction vessel made of Inconel-625 to which thermocouple and pressure gauge were attached for the measurement of temperature and pressure. It was then subjected to various subcritical conditions of phenol $\left(\mathrm{T}_{\mathrm{c}}=421.2^{\circ} \mathrm{C}, \mathrm{P}_{\mathrm{c}}=6.13 \mathrm{MPa}\right)$ as shown in Table 1 , by immersing its reaction vessel into the molten salt bath of $\mathrm{KNO}_{3}$ (supplied by Parker Netsushori, Kogyo Co. Ltd, Japan) preheated at a designated temperature. Such a wide range of treatment conditions was chosen to study the liquefaction behavior and the whole utilization of biomass in a better way. 
The reaction vessel was oscillated inside the molten salt bath to maintain the homogenous mixing inside the vessel and for proper heat transfer. The treatment time mentioned here in this study, includes the total time from insertion into the molten salt bath for a designated treatment time. It takes less than a minute to bring the sample to the reaction temperature inside the reaction vessel, therefore, the starting points are always neglected in calculating the data points for the kinetic study. After the treatment, the reaction vessel was dipped into water bath maintained at ambient temperature to stop the reaction.

The resulting reaction mixture was then filtered with Polytetrafluoroethylene (PTFE) filters (ADVANTEC, Japan) of $0.2-\mu \mathrm{m}$ pore size and $47 \mathrm{~mm}$ diameter, under negative pressure and the phenol-soluble portion was separated from phenol-insoluble residue. Its residue was then washed properly with reagent grade methanol from Nacalai Tesque Inc., Japan, to remove phenol. The obtained residue was then oven-dried for 12 hours at $105^{\circ} \mathrm{C}$ and transferred to desiccators for cooling to determine the weight percent content, as phenol-insoluble residue. For lignin in its residue, the Klason lignin content and the acid-soluble lignin were determined (Dence, 1992). The amounts of constituent monosaccharides in the phenol-insoluble residue were determined by high-performance liquid chromatography (HPLC) for the clear filtrate from acid hydrolysates in the Klason lignin determination (Wörmeyer et al., 2011). Such HPLC analysis were carried out with a Shimadzu LC-10A system under the following conditions: column, Aminex HPX-87P (Bio-Rad) of $300 \times 7.8 \mathrm{~mm}$ dimensions; flow-rate $1.0 \mathrm{ml} / \mathrm{min}$; eluent, distilled water; detector, refractive-index detector RID-10A; temperature, $40^{\circ} \mathrm{C}$. The cellulose and 
hemicellulose contents in the phenol-insoluble residue were then estimated according to literature (Agblevor et al., 2004, Sluiter et al., 2004).

In such a manner, the weight percent contents of the major cell wall components (cellulose, hemicellulose and lignin) were obtained. Such data were collected after repeating the experiments thrice, in order to check the variations. Less than $2 \%$ variations were recorded, suggesting that the experiments can be replicated and data can be reproduced anytime and anywhere, by keeping the same treatment conditions. The weight percent contents of major cell wall components were used for the calculation of their individual liquefaction rate constant at various treatment conditions, based on the assumed first-order reaction rate kinetics for their liquefaction. The temperature dependence of its rate constant was then studied as per the Arrhenius Equation. The activation energies were, therefore, determined based on the slope of their respective curves on the Arrhenius plot between the natural logarithm of the liquefaction rate constant $k$ and $\mathrm{T}^{-1}$ (Kelvin).

\section{Results and discussion}

3.1 Liquefaction behaviors of Japanese beech by subcritical phenol treatment

The solvent of phenol used in this study has a critical point at $421.2^{\circ} \mathrm{C} / 6.13 \mathrm{MPa}$ (Ambrose, 1963, Nikitin et al., 2007). This critical point is remarkably high for liquefaction of wood. Therefore, subcritical conditions were selected as milder treatments in a range between $160^{\circ} \mathrm{C} / 0.9 \mathrm{MPa}$ and $350^{\circ} \mathrm{C} / 4.2 \mathrm{MPa}$ for $3-30 \mathrm{~min}$, so as to minimize 
the thermal decomposition of wood. The treated sample was then fractionated into phenol-soluble portion and phenol-insoluble residue. Fig. 1 shows the obtained changes in the phenol-insoluble residues at various conditions. Such trends are non-linear and in exponential logarithmic function, thus the first-order reaction kinetics may be used for its mechanism (Xin et al., 2009).

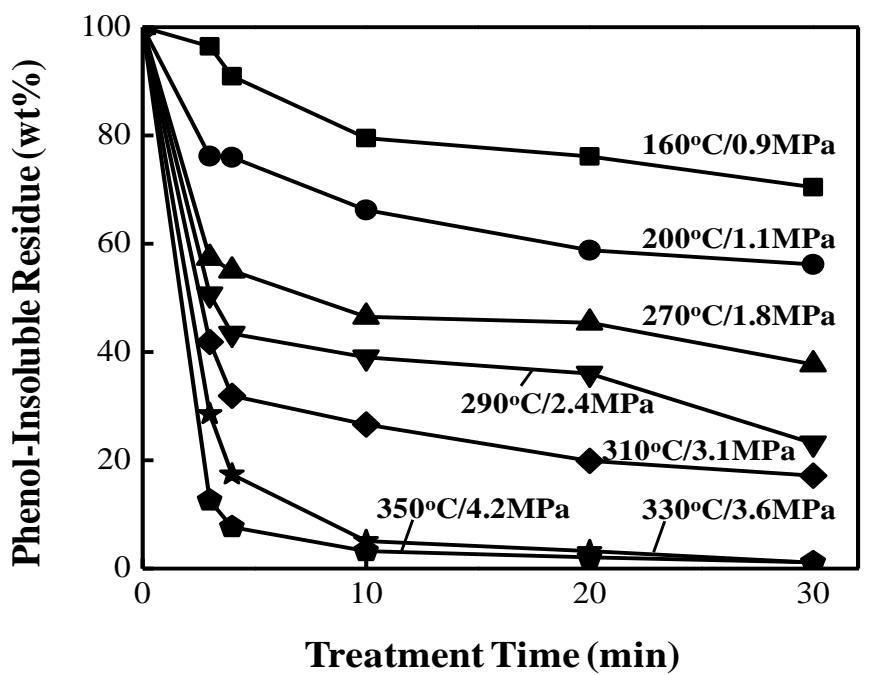

Fig. 1. Changes in the phenol-insoluble residues of Japanese beech as treated in subcritical phenol at various conditions.

As Japanese beech was subjected to various subcritical conditions, the initial amount of the phenol-insoluble residue denoted as $W_{\text {in }}(100 \mathrm{wt} \%)$ decreased and, in turn, phenol-soluble portion increased, which can be obtained by $W_{i n}(100 \mathrm{wt} \%)$ minus phenol-insoluble residue (wt \%). At treatment temperatures in a range between $160^{\circ} \mathrm{C}$ and $200^{\circ} \mathrm{C}$, Japanese beech was modestly liquefied and phenol-insoluble residues for more than $60 \mathrm{wt} \%$ was left, even after $30 \mathrm{~min}$ treatment time. At $270^{\circ} \mathrm{C} / 1.8 \mathrm{MPa}$, the phenol-insoluble residue was reduced to $40 \%$. On further increasing the treatment temperature, Japanese beech was liquefied more, and at the highest temperature of $350^{\circ} \mathrm{C}$, 
it was efficiently liquefied, with less than $10 \mathrm{wt} \%$ phenol-insoluble residue left after the 4 min treatment time.

3.2 Liquefaction Kinetics of Japanese beech and its cell wall components

The rate of liquefaction of Japanese beech in subcritical phenol was considered on a basis of the kinetics of the first-order reaction as in Eq. (1)

$\frac{d W}{d t}=-k W$

where $W$ is the oven-dried weight of Japanese beech used in the study, $t$ the treatment time at which Japanese beech was subjected to various subcritical conditions of phenol, and $k$ the liquefaction rate constant. The Eq. (1) has led to Eq. (2), which is further rearranged into Eq. (3), in which $W_{i n}$ and $W_{f}$ are, respectively, the initial and final ovendried weights of the residue in subcritical phenol at the initial and final treatment times ( $t_{\text {in }}$ and $t_{f, \text { respectively). }}$

$\frac{d W}{W}=-k d t$

$\ln \left(\frac{W_{i n}}{W_{f}}\right)=-k\left(t_{\text {in }}-t_{f}\right)$

The first-order reaction kinetics was used for the liquefaction mechanism. The liquefaction rate constant $k$ of the three major cell wall components was determined based on the weight percent contents as mentioned in Table 1, by plotting the respective 
points between their $\ln \left(W_{i n} / W_{f}\right)$ and $\left(t_{i n}-t_{f}\right)$, treated in a temperature range between $160^{\circ} \mathrm{C}$ and $350^{\circ} \mathrm{C}$ for $3-30 \mathrm{~min}$.

Fig. 2 shows the obtained temperature dependence of the liquefaction rate constant of these cell wall contents, cellulose, hemicellulose and lignin under high pressure (0.9-4.2MPa). The individual data points on the curves, therefore, provide the liquefaction rate constants for the cell wall components at particular treatment conditions.

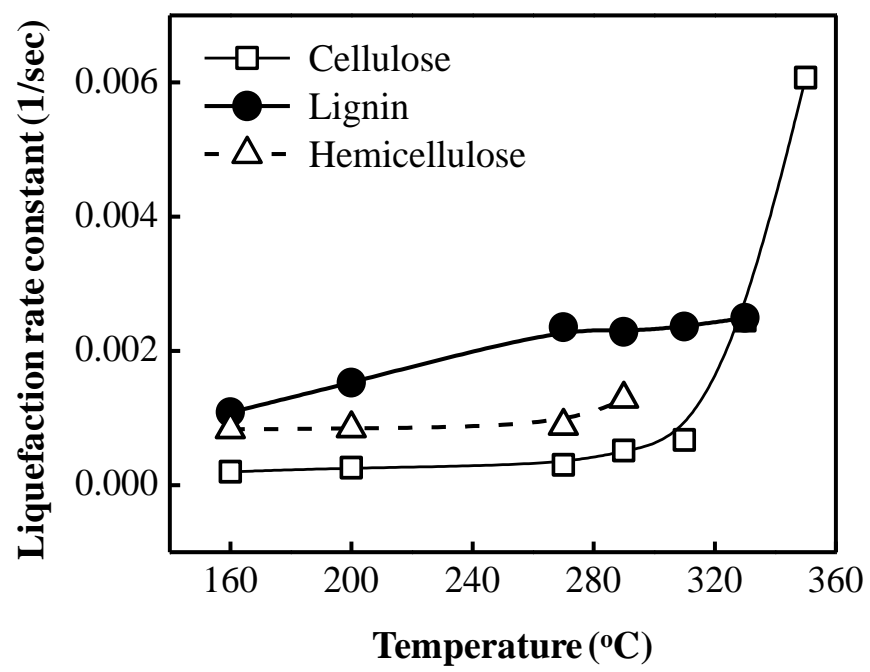

Fig. 2. Comparison of liquefaction rate constant of the major cell wall components of Japanese beech at various subcritical conditions of phenol.

It could be seen that, in the low temperature range $\left(160^{\circ} \mathrm{C}-290^{\circ} \mathrm{C}\right)$, the liquefaction rate constant did not change much for cellulose which may be explained by its crystalline nature. Thus, cellulose was difficult to be decrystallized in this low temperature range. On increase in temperature from $310^{\circ} \mathrm{C}$ onwards, a sharp increase in liquefaction rate constant of cellulose was noticed, which could suggest the destruction of its crystalline structure. On the other hand, the hemicellulose and lignin being amorphous 
in nature show a similar trend in low temperature range, with higher liquefaction rate compared to cellulose. Above $290^{\circ} \mathrm{C}$, the liquefaction rate constant of hemicellulose was unable to be determined, due to the complete removal of hemicellulose, whereas the remaining lignin continued to be liquefied. It is apparent that the liquefaction rate constant of lignin in the lower temperature range is gradually increasing, but above $290^{\circ} \mathrm{C}$, it became almost constant.

Table 1. The whole wood of Japanese beech and its insoluble-residue yield of major cell wall components as treated by various subcritical conditions of phenol.

\begin{tabular}{|c|c|c|c|c|}
\hline \multirow{2}{*}{ Reaction Condition } & \multicolumn{4}{|c|}{ Yield (wt\%) } \\
\hline & Cellulose & Hemicellulose & Lignin & Whole wood \\
\hline Untreated & $45 \_0$ & 30_o & $25 \_0$ & 100_o \\
\hline 160'C/0_9MPa/3min & 427 & 125 & $9 \_1$ & $96 \_5$ \\
\hline 4 min & 421 & $9 \_1$ & 92 & $90 \_9$ \\
\hline 10min & 37.6 & 9.1 & $7 \ldots 1$ & 78.5 \\
\hline 20min & 324 & $8 \_6$ & 49 & $76 \_1$ \\
\hline 30 min & 31.7 & 6.8 & 35 & $70 \_4$ \\
\hline $200 \times C / 1 / 1 M P a / 3 \min$ & 40.4 & 119 & 89 & 76.2 \\
\hline 4 min & 415 & 11 7 & 7.7 & 75.9 \\
\hline 10min & $35 \_1$ & 9.7 & 3.8 & 66.2 \\
\hline 20min & 321 & 115 & 29 & 58.8 \\
\hline 30min & 282 & 6.6 & 1.6 & 56.2 \\
\hline $270 \times C / 1$ gMPar $3 \min$ & 43.1 & 93 & 39 & 57.4 \\
\hline $4 \min$ & 385 & 13 -4 & 33 & 55.0 \\
\hline 10min & $34 \_6$ & 92 & $\mathrm{o}_{-7} 7$ & $46 \_5$ \\
\hline 20 min & 29.7 & $12 \_0$ & $\mathbf{0} 5$ & 45.4 \\
\hline 30min & 263 & 62 & $\mathbf{o}_{3}$ & 37.7 \\
\hline $290 \times C / 24 \mathrm{MPa} / 3 \min$ & 433 & 4 & 63 & 50.7 \\
\hline 4min & 40.6 & 3 & 42 & 43.4 \\
\hline 10min & 305 & 32 & 1.8 & 39_0 \\
\hline 20 min & 28.6 & $\mathbf{0}$ & 1 & $36 \_0$ \\
\hline 30min & 17.8 & $\mathbf{0}$ & 1 & 23.1 \\
\hline $310^{\circ} \mathrm{C} / 3 \_1 \mathrm{MP} / 3_{\min }$ & 39.0 & 1.7 & 29 & 41.8 \\
\hline 4 min & 3488 & $\mathbf{0}$ & $2 \ldots$ & 31.9 \\
\hline 10min & 25.6 & $\mathbf{0}$ & $\mathbf{1}$ & 26.6 \\
\hline 20 min & 18.8 & $\mathbf{0}$ & 0.7 & 229 \\
\hline 30min & 115 & $\mathbf{0}$ & $\mathbf{0}_{-4}$ & $21-4$ \\
\hline $330 \times C / 3,6 M P a / 3 \min$ & 213 & 15 & 19 & 28.5 \\
\hline $4 \min$ & 143 & $\mathbf{o}$ & 1 & 17.4 \\
\hline 10min & 24 & $\mathbf{0}$ & 0.4 & 5.1 \\
\hline 20min & $\mathbf{0}$ & $\mathbf{0}$ & 0_02 & 3_2 \\
\hline 30min & $\mathbf{0}$ & $\mathbf{0}$ & 0_o1 & 1 \\
\hline $350 \times C / 42 \mathrm{MPa} / 3 \min$ & 215 & 13 & $\mathbf{0} 5$ & 126 \\
\hline $4 \min$ & 10.8 & $\mathbf{0}$ & $\mathbf{0}_{3}$ & $\mathbf{7} 7$ \\
\hline 10min & 1_1 & $\mathbf{0}$ & $\mathbf{0}$ & 3.2 \\
\hline 20 min & $\mathbf{0}$ & $\mathbf{0}$ & $\mathbf{0}$ & 21 \\
\hline 30min & $\mathbf{0}$ & $\mathbf{0}$ & $\mathbf{0}$ & $0 \_9$ \\
\hline
\end{tabular}


The chemistry of all three major cell wall components of wood was explained in a better way as shown in Fig. 3. It reveals the decomposition followed by liquefaction of cellulose, hemicellulose and lignin in two different temperature ranges, suggesting the existence of the two different kinetic mechanisms. At lower temperature range $\left(160^{\circ} \mathrm{C}-\right.$ $290^{\circ} \mathrm{C}$ ), the amorphous substances of wood would be more liquefied like hemicellulose and lignin, whereas at higher temperature range $\left(310^{\circ} \mathrm{C}-350^{\circ} \mathrm{C}\right)$, the destruction of crystalline cellulose along with the substantial removal of the amorphous hemicellulose and lignin would be taken place. However, hemicellulose being the amorphous polymer was mostly liquefied only at lower temperature range.

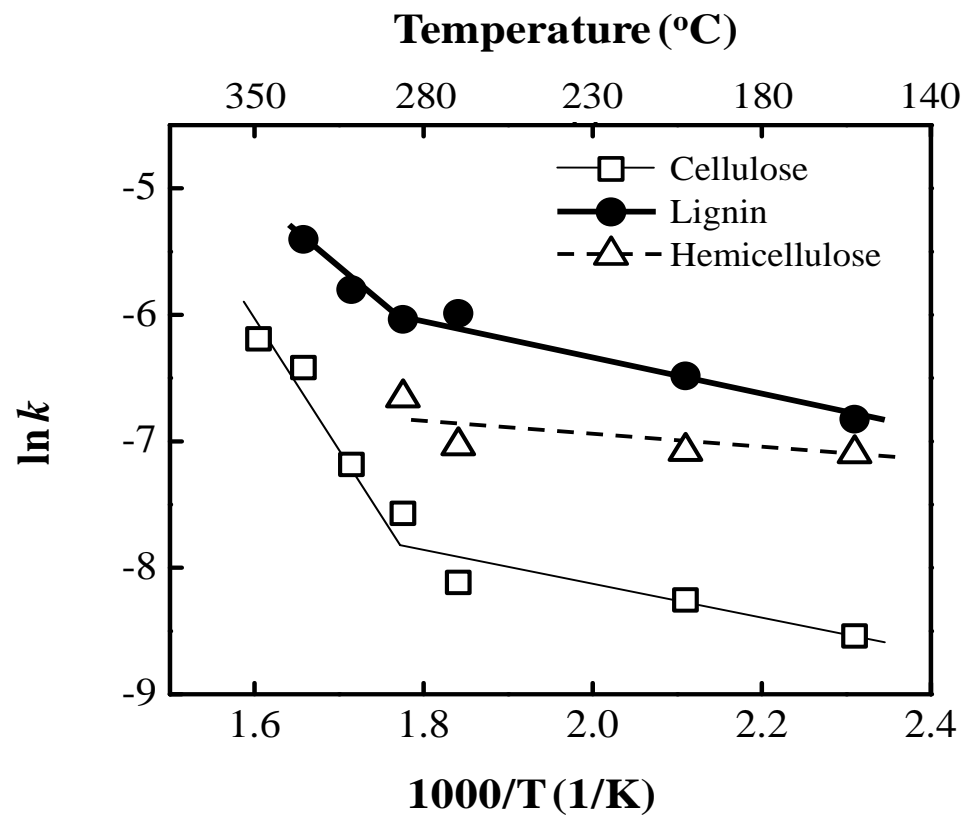

Fig. 3 Temperature dependence of the logarithm (ln) of liquefaction rate constant $(k)$ of the major cell wall components of Japanese beech. 
On the other hand, the lignin was continued to be liquefied even at higher temperature range. Thus, two different liquefaction mechanisms must exist for lignin. According to the literature (Freudenberg, K., 1932, Adler, E., 1977, Monties, 1994), two different kinds of linkages exist in lignin macromolecules such as non-condensed ether linkages and condensed carbon-carbon (C-C) linkages. In the lower temperature range, therefore, the cleavage of ether linkages would take place in lignin, whereas the cleavage of carbon-carbon linkages, which has resistance against liquefaction in lower temperature range, would possibly take place at higher temperature range. The cleavage of such bonds in lignin macromolecule at different temperature ranges are in good agreement with literature (Pandey and Kim, 2011).

Cellulose being mainly crystalline in nature, on the other hand, consists of some para-crystalline structure in it which is assumed to get decomposed and liquefied to some extent in the lower temperature range, whereas most of the crystalline cellulose was suggested to be decomposed and liquefied at the higher temperature range, leading to the substantial destruction of its crystalline structure. This is in good agreement with the change in the apparent crystallinity of cellulose with different subcritical treatment conditions (Mishra and Saka, 2010).

In order to check whether the individual liquefaction rate constant $k$ for all three major cell wall components satisfies the Arrhenius equation as Eq. (4), a relation between ln $k$ and $T^{-1}$ shown in Eq. (5) was obtained by taking the natural logarithm of Eq. (4).

$$
k=A \exp \left(\frac{-E_{a}}{R T}\right)
$$


$\ln k=-\frac{E_{a}}{R T}+B$

where $E_{a}$ is activation energy, $R$ ideal gas law constant $(8.314 \mathrm{~J} / \mathrm{mol} \mathrm{K}), B$ a constant that intercepts the straight line to vertical axis, and $A$ the pre-exponential factor.

Activation energy of any reaction mainly explains its degree of temperaturesensitiveness; reactions with high activation energies are very temperature-sensitive, while the reactions with low activation energies are low in temperature-sensitiveness (Xin et al., 2009). It can also be said that activation energy is defined as the minimum energy required for liquefaction, denoted by $E_{a}$. The smaller $E_{a}$ for liquefaction of any particular component signifies the requirement of less energy for its liquefaction, whereas the larger $E_{a}$ suggests more energy for liquefaction of that component.

In Table 2, the obtained activation energies for such two temperature ranges are shown. In lower temperature range, the activation energy for hemicellulose ( $E_{a \text { (hemicellulose) }}$ $=6.9 \mathrm{KJ} / \mathrm{mol}$ ) is lowest, suggesting that its complete liquefaction can be achieved at lower temperature treatments. The activation energy associated with cellulose ( $E_{a \text { (cellulose) }}$ $=15.2 \mathrm{KJ} / \mathrm{mol}$ ) at the same temperature range is higher than those of hemicellulose and lignin $\left(E_{a(\text { lignin })}=12.4 \mathrm{KJ} / \mathrm{mol}\right)$. This suggests that cellulose requires much higher energy for its liquefaction as compared to hemicellulose and lignin and thus get liquefied at higher temperature treatments. 
Table 2. Activation Energies of the different cell wall components of Japanese beech on its liquefaction as treated with subcritical phenol for 3 - 30min.

\begin{tabular}{lcc}
\hline \multirow{2}{*}{$\begin{array}{c}\text { Cell Wall } \\
\text { Component }\end{array}$} & \multicolumn{2}{c}{ Activation Energy $(\mathrm{KJ} / \mathrm{mol})$} \\
\cline { 2 - 3 } & $\begin{array}{c}\text { Low temperature range } \\
\left(160^{\circ} \mathrm{C}-290^{\circ} \mathrm{C}\right)\end{array}$ & $\begin{array}{c}\text { High temperature range } \\
\left(310^{\circ} \mathrm{C}-350^{\circ} \mathrm{C}\right)\end{array}$ \\
\hline Cellulose & 15.2 & 74.9 \\
Hemicellulose & 6.9 & - \\
Lignin & 12.4 & 65.7 \\
\hline
\end{tabular}

In higher temperature range, the phenol-insoluble residue consists of only cellulose and lignin due to the complete removal of hemicellulose at lower temperature treatments. As shown in Table 2, the activation energy for the liquefaction of cellulose $\left(E_{a \text { (cellulose) }}=74.9 \mathrm{KJ} / \mathrm{mol}\right)$ is higher than that of lignin $\left(E_{a \text { (lignin) }}=65.7 \mathrm{KJ} / \mathrm{mol}\right)$, which can be justified by more energy required for the substantial destruction of its crystalline structure as compared to the energy required in cleaving mainly the $\mathrm{C}$ - $\mathrm{C}$ linkages of lignin. The activation energies thus obtained from Fig. 3 can suggest the two different kinetic mechanisms to exist for cellulose and lignin, whereas amorphous hemicellulose can be liquefied by only single kinetic mechanism at lower temperature range.

\section{Concluding remarks}

The liquefaction of Japanese beech was achieved successfully in phenol at various subcritical conditions and the total treatment time in liquefying it, has been successfully 
reduced as compared to non-catalytic liquefaction with methanol or ethanol. The increase in its liquefaction rate constant was found with a rise in the treatment temperature under similar treatment pressures. The evaluation of liquefaction rate constants of the major cell wall components suggested that in the lower temperature range $\left(160^{\circ} \mathrm{C}-290^{\circ} \mathrm{C}\right)$, the cellulose did not take much part in the liquefaction process, thus not decomposed much due to its high crystalline structure, whereas, the hemicellulose being the amorphous substance got liquefied almost completely, and lignin was liquefied partially in such lower temperature range. The lignin and cellulose were later completely liquefied into phenol at higher temperature treatments $\left(310^{\circ} \mathrm{C}-350^{\circ} \mathrm{C}\right)$. The two different kinetic mechanisms were thus suggested for lignin and cellulose liquefaction. The activation energies in liquefaction for cellulose, lignin and hemicellulose at both lower and higher temperature ranges shows that hemicellulose is liquefied first, and lower temperature conditions are sufficient for its liquefaction, whereas the lignin requires higher temperature conditions compared to the hemicellulose, but milder than the conditions required for cellulose liquefaction. These lines of evidence are in good agreement with knowledge of the chemical composition and physicochemical properties of wood as a natural composite material.

Acknowledgement This work was accomplished under financial support from Kyoto University Global Center of Excellence (GCOE) Energy Science Program sponsored by the Ministry of Education, Science, Sports and Culture, Japan. 


\section{References}

Adler, E., 1977. Lignin chemistry-past, present and future. Wood Sci Technol., 11, 169218.

Agblevor, F.A., Murden, A., and Hames, B.R., 2004. Improved method of analysis of biomass sugars using high-performance liquid chromatography. Biotechnol. Lett., 26, 1207-10.

Alma, M.H., Maldas, D., and Shinraishi, N., 1998. Liquefaction of several biomass wastes into phenol in presence of various alkalis and metallic salts as catalysts. J. Polym. Eng. 18, 161-77.

Ambrose, D., 1963. Critical temperatures of some phenols and other organic compounds. Trans. Faraday Soc., 59, 1988-93.

Damartzis, T., Zabaniotou, A., 2011. Thermochemical conversion of biomass to second generation biofuels through integrated process design-A review. Renew. Sust. Energy Rev. 15, 366-78.

Dence, C.W., 1992. The determination of lignin. In: Lin S.Y., Dence C.W. (ed) Methods in lignin chemistry. Springer, Berlin, Germany, 33-63. 
Freudenberg, K., 1932. The relation of cellulose to lignin in wood. J. Chem. Educ. 9, 1171-80.

Hassan, E.M., Shukry, N., 2008. Polyhydric alcohol liquefaction of some lignocellulosic agricultural residues. Ind. Crop Prod. 27, 33-38.

Lee, S.H., Ohkita, T., 2003. Rapid wood liquefaction by supercritical phenol. Wood Sci Technol. 37, 29-38.

Maldas, D., Shiraishi, N., 1997. Liquefaction of biomass in the presence of phenol and $\mathrm{H}_{2} \mathrm{O}$ using alkalies and salts as the catalyst. Biomass Bioenerg. 12, 273-79.

McKendry, P., 2002. Energy production from biomass (part 2): conversion technologies. Bioresour. Technol. 83, 47-54.

Minami, E., Kawamoto, H., Saka, S., 2003. Reaction behavior of lignin in supercritical methanol as studied with lignin model compounds. J Wood Sci 49, 158-65.

Minami, E., Saka, S., 2003. Comparison of the decomposition behaviors of hardwood and softwood in supercritical methanol. J Wood Sci 49, 73-78.

Minami, E., Saka, S., 2005. Decomposition behavior of woody biomass in water-added supercritical methanol. J Wood Sci 51, 395-400. 
Mishra,G., Saka, S., 2010. Liquefaction behaviors of Japanese beech as treated in subcritical phenol, In: Yao T (ed) Zero-Carbon Energy Kyoto 2010, Green Energy and Technology, Springer, 147-152.

Monties, B., 1994. Chemical assessment of lignin biodegradation some qualitative and quantitative aspects. FEMS Microbiology Rev. 13, 277-84.

Nikitin, E.D., Popov, A.P., Yatluk, Y.G., 2007. Vapor-Liquid critical properties of phenol and (C8 to C10) phenylalkanols. J. Chem. Eng. Data 52, 315-17.

Pandey, M.P., Kim, C.S., 2011. Lignin Depolymerization and Conversion: A Review of Thermochemical Methods. Chem. Eng. Technol. 34, 29-41.

Saka, S., 2006. Recent progress in supercritical fluid science for biofuel production from woody biomass. For. Stud. China 8, 9-15.

Sluiter, A., Hames, B., Ruiz, R., Scarlata, C., Sluiter, J., Templeton, D., 2004. Determination of structural carbohydrates and lignin in biomass. NREL Laboratory $\begin{array}{llll}\text { Analytical } & \text { Procedures. } & \text { Available }\end{array}$ <http://www.eere.energy.gov/biomass/analytical_procedures.html> 
Wen, D., Jiang, H., Zhang, K., 2009. Supercritical fluids technology for clean biofuel production. Prog Nat Sci. 19, 273-84.

Wörmeyer, K., Ingram, T., Saake, B., Brunner, G., Smirnova, I., 2011. Comparison of different pretreatment methods for lignocellulosic materials. Part II: Influence of pretreatment on the properties of rye straw lignin. Bioresour. Technol. 102, 4157-64.

Xin, J., Imahara, H., Saka, S., 2009. Kinetics on the oxidation of biodiesel stabilized with antioxidant. Fuel, 88, 282-86.

Yan, Y., Hu, M., Wang, Z., 2010. Kinetic study on the liquefaction of cornstalk in polyhydric alcohols. Ind. Crop Prod., 32, 349-52.

Yamazaki, J., Minami, E., Saka, S., 2006. Liquefaction of beech wood in various supercritical alcohols. Mokuzai Gakkaishi, 52, 527-32.

Yao, Y., Yoshioka, M., Shiraishi, N., 1994. Soluble properties of liquefied biomass prepared in organic solvents I. The soluble behavior of liquefied biomass in various diluents. Mokuzai Gakkaishi, 40, 176-84. 